\title{
ARRANJOS VIOLENTOS E ESPERANÇA: \\ COMO A LINGUAGEM DOS DIREITOS HUMANOS OPEROU NUM ATENTADO EM FORTALEZA, CE
}

\author{
VIOLENT ARRANGEMENTS AND HOPE: \\ HOW THE LANGUAGE OF HUMAN RIGHTS WAS ENACTED \\ AFTER A TERRORIST ATTACK IN FORTALEZA, CE, BRAZIL
}

\section{Daniel do Nascimento e Silva* Claudiana Nogueira Alencar $^{* *}$}

\section{RESUMO}

Este artigo tem por objetivo descrever algumas formas de resistência a arranjos violentos contemporâneos - entendidos como as relações tensas, no Brasil, entre grupos do crime organizado violento e entre estes e o mundo público - que emergiram na fala de pessoas que sobreviveram ou foram afetadas por um atentado terrorista no bairro do Benfica, em Fortaleza, CE, ocorrido em março de 2018. Em linha com outros estudos sobre formas de florescimento subjetivo e coletivo em circunstâncias de violência ou destruição política, damos o nome a essa forma de resistência de 'esperança'. A partir de entrevistas com dois sobreviventes do atentado, uma professora e um ativista de direitos humanos, defendemos que ter esperança, nesses diálogos que buscavam ressignificar uma fratura, significou responder à violência não por meio de vingança ou de mecanismos extralegais ou excepcionais de violência reativa mas por meio de tropos que informam a defesa dos direitos humanos.

Palavras-chave: esperança; direitos humanos; metapragmática; violência.

\section{ABSTRACT}

This paper describes some forms of resistance to contemporary violent arrangements - understood as the tense relations, in Brazil, between groups of the violent organized crime and between the latter and the public world - which have emerged in the speech of people who survived or were affected by a terrorist attack in the neighborhood of Benfica, in Fortaleza, Ceará, Brazil, occurred in March, 2018. In line with other studies about forms of subjective and collective flourishing in circumstances of violence or political destruction, we will term this form of resistance as 'hope'. By engaging with two interviews conducted with two survivors, a professor, and a human rights' activist, we argue that hope, in these dialogues, amounted to responding to violence not by means

\footnotetext{
* Universidade Federal de Santa Catarina, Florianópolis (SC), Universidade Federal do Rio de Janeiro, Rio de Janeiro (RJ), Brasil. dnsfortal@gmail.com.

** Universidade Estadual do Ceará (UECE), Fortaleza (CE), Brasil. claunoce@gmail.com.
} 
of vengeance or extralegal mechanisms of violence but by using tropes that inform the defense of human rights.

Keywords: hope; human rights; metapragmatics; violence.

\section{PANO DE FUNDO: ARRANJOS VIOLENTOS ENTRE MUNDO DO CRIME E MUNDO PÚBLICO}

9 de março, 2018. Aquela parecia uma sexta-feira à noite como qualquer outra no boêmio bairro do Benfica, em Fortaleza. Como de costume, dezenas de jovens encontravam-se reunidos, sentados às diversas mesas dos bares que circundam a Praça da Gentilândia, importante espaço de socialização da juventude na região central de Fortaleza. À medida que a noite avançava, outros jovens reuniam-se aos demais, vindos da cerimônia de formatura que acontecera na Concha Acústica do histórico casarão da Reitoria da Universidade Federal do Ceará, a pouco mais de cem metros da praça. A rotina festiva daquela noite seria rompida às $23 \mathrm{~h} 30$, quando estacionou um Honda Civic, de onde saíram dois homens armados. Por mais de 10 minutos, um dos atiradores disparou tiros contra as pessoas que estavam no local. Três pessoas morreram imediatamente e várias outras foram atingidas por tiros e estilhaços. Outras se feriram ao se jogarem num chão repleto de pedaços de copos e garrafas. Um mês após o ocorrido, enquanto escrevemos este relato, algumas delas continuam internadas em estado grave.

Simultaneamente a esse ataque, um Fiat Punto com três homens se aproximava da sede da Torcida Uniformizada do Fortaleza, TUF. Localizada na Vila Demétrio, a menos de $1 \mathrm{~km}$ da Praça da Gentilândia, a sede da TUF costuma ser o ponto de encontro de torcedores do Fortaleza, um dos principais times de futebol do Ceará, que se reúnem para fazer churrasco e socializar às sextas-feiras. Do Fiat Punto, desceram dois homens, que desferiram tiros contra as pessoas que se reuniam no local. Uma pessoa morreu imediatamente. Outra vítima viria a morrer no hospital. A poucos metros dali, na Rua Joaquim Magalhães, os atiradores também atingiram um motociclista e a pessoa que estava na garupa, ambos uniformizados com a camisa do Fortaleza. Um dos atingidos morreu na hora; o outro não sobreviveu aos ferimentos e faleceu no hospital.

Orquestradas por dois grupos de atiradores que agiam em concerto, as ações são atribuídas à GDE, ou Guardiões do Estado, uma facção criminosa recentemente criada no Ceará, em reação ao estabelecimento no Estado de outras facções brasileiras, como o Primeiro Comando da Capital (PCC), de São Paulo, o Comando Vermelho (CV), do Rio de Janeiro, e a Família do Norte (FDN), do Amazonas. 
Como discutiremos a seguir, esses grupos vivem em clima de permanente tensão, eventualmente aliando-se para guerrear contra uma facção rival (o Comando Vermelho é aliado da FDN no Ceará e, ocasionalmente, a GDE se une ao PCC para rivalizar com o Comando Vermelho) ou promovendo breves pactos de "pacificação" (PAIVA, 2018).

Naquela noite, atiradores vinculados à GDE mataram 7 pessoas, deixaram pelo menos outras 7 gravemente feridas e espalharam pânico em diferentes locais de um movimentado bairro central. As ações coordenadas foram classificadas por um dirigente da TUF e por uma de nossas interlocutoras no campo como "ato terrorista" (apud CAVALCANTE, 2018). Investigações da Polícia Civil divulgadas na imprensa indicam que, contrariamente a hipóteses iniciais, esse atentado terrorista não foi motivado por disputas entre torcidas organizadas. Em depoimento à Polícia Civil, Douglas Matias da Silva, capturado um dia após o atentado, afirmou que os atos foram motivados por vingança, "no contexto da disputa entre facções criminosas por territórios na Capital" (MAZZA, 2018). No depoimento, Douglas Silva, que participou do atentado na sede da TUF, admitiu ser membro da GDE, grupo que disputa território econômico e simbólico com o Comando Vermelho. Em janeiro de 2018, a GDE havia realizado aquela que ficaria conhecida como a maior chacina do Ceará, matando 14 jovens, 8 das quais mulheres, num baile de forró no bairro de Cajazeiras, na periferia de Fortaleza. Disputas pelos mercados varejistas de drogas e por outros serviços ilícitos entre Guardiões do Estado e Comando Vermelho são apontadas como motivadoras desse crime.

A tragédia que se abateu sobre o bairro do Benfica e que afetou estudantes, professores e moradores é sintomática de uma questão que vem sendo delineada pelos estudos sobre a violência no Brasil, em especial pelo trabalho sociológico de Luiz Machado da Silva (1999) e reelaborada pelo trabalho etnográfico de Gabriel Feltran (2012) e Ana Paula Galdeano (2017). Em outras palavras, a matança efetuada por aquela facção criminosa e o tipo de enunciação que ela estabelece no espaço público acontecem no contexto da convivência ou sobreposição, no Brasil, de dois regimes normativos distintos: o ordenamento estatal e o crime violento organizado. Machado da Silva havia lançado a hipótese sobre a correlação desses dois ordenamentos distintos no fim da década de 1990, como explicação para o caráter organizado - em vez de aleatório e instrumental - do crime violento que surgia nas cidades brasileiras a partir dos anos 1970. Ainda nos termos dessa hipótese, o crime violento coexistiria com outro regime normativo distinto - o do Estado - e não teria as condutas da ordem pública como referência (MACHADO DA SILVA, 1999). Essa hipótese viria a ser confirmada - com algumas modificações - nos trabalhos etnográficos 
que citamos acima ${ }^{1}$. Comentando a especificidade da convivência desses regimes normativos nas periferias de São Paulo, Feltran e Galdeano têm demonstrado que o mundo do crime se transformou numa "instância de autoridade" (GALDEANO, 2017, p. 53) para os moradores, alcançando uma legitimidade nesses territórios que coexiste, de forma tensa e conflitiva, com a legitimidade do Estado.

Em São Paulo, a convivência e mútua relação desses regimes normativos extrapolam as fronteiras das periferias e afetam a vida de forma mais ampla. Gabriel Feltran (2012) argumenta que a redução dos números de homicídios em São Paulo, a partir de 2001, alardeada pelo governo do Estado como um feito de sua política de segurança pública, tem sido menos o resultado do encarceramento em massa implementado pela última do que de medidas e estratégias adotadas pelo PCC, facção hegemônica no Estado, que passou a mediar as condutas do mundo do crime nos presídios e nas periferias. Com um senso de justiça próprio, o PCC instituiu em São Paulo um mecanismo de regulação e controle dos mercados ilícitos de drogas, desmanches de carros, assaltos, entre outros; nesse mecanismo, que regula também as disposições morais de seus membros, o homicídio não é mais a chave de resolução de conflitos, mas sim os debates entre os "irmãos" que compõem esse coletivo. Assim, "aquele menino que antes devia matar um colega por uma dívida de $\mathrm{R} \$ 5$, para ser respeitado entre seus pares, agora não pode mais matá-lo: deve recorrer ao PCC para reivindicar uma reparação do dano sofrido" (FELTRAN, 2012, p. 241). Essa nova ética do crime interrompeu, em São Paulo, um ciclo de vingança que geraria outras mortes - o irmão do colega poderia tentar vingá-lo, e assim sucessivamente -, o que impactou os números de morte violenta no estado, ainda que outros crimes, como roubos e assaltos, tenham crescido nesse período. $O$ resultado, defende Feltran (2012), foi uma redução de $70 \%$ dos assassinatos em São Paulo, no período de 2001 a 2011. No Ceará, um acordo entre facções rivais nos anos de 2015 e 2016, que ficou conhecido como "pacificação", reduziu significativamente o número de homicídios no estado. De acordo com o Anuário Brasileiro de Segurança Pública de 2017, entre 2015 e 2016, as mortes violentas intencionais no Ceará foram reduzidas de 46,4 para 39,8 pessoas por mil habitantes; esse número implicou uma redução de 14,2\%, a segunda maior do país, depois do Amazonas, cujo decréscimo foi de 19,9\% (FÓRUM BRASILEIRO DE SEGURANÇA PÚBLICA, 2017). João Paulo Barros, Luiz Fábio Paiva, Jéssica Rodrigues, Dagualberto Silva e Camila Leonardo, pesquisadores da UFC, explicam que a breve "pacificação" consistiu "na proibição do ciclo de vinganças e práticas de homicídio entre grupos locais" (BARROS et al, 2018, p.118). Nesse breve arranjo de "paz", a política do crime no Ceará, segundo

1. Para uma etnografia do regime normativo do PCC nos presídios de São Paulo, ver BIONDI (2014). 
os autores, teve suporte de "grupos que atuam nos mercados ilegais de drogas e armas em escala nacional". Disputando espaço e legitimidade, políticas de governo e políticas do crime, segundo Feltran (2012), têm diferencialmente legislado sobre a vida e a morte nos territórios urbanos, funcionando como regimes normativos que as pessoas, também diferencialmente, experimentam em seu cotidiano.

A sequência brutal de assassinatos no Benfica - justificada por um de seus autores como "vingança" entre facções e posicionada por um sobrevivente, a quem entrevistamos, como um "ato excessivamente violento... pra mandar uma mensagem" - são um indício de que os arranjos no interior do mundo do crime ("era uma vingança") e entre este e o mundo público ("era pra mandar uma mensagem") são violentos, i.e., situam a disputa por espaço político e simbólico no campo da força. 'Arranjos violentos' é, assim, a expressão que utilizamos neste texto para falar de um pano de fundo - as relações tensas, no Brasil e mais especificamente no Ceará, entre grupos do crime organizado violento e entre estes e o mundo público -, contra o qual contrastamos uma figura, isto é, a resistência de pessoas que foram marcadas, de diferentes formas, pelo atentado terrorista no Benfica, a ele respondendo em termos de valores e racionalizações que são contrários à força, à vingança e à desigualdade. Em linha com outros estudos sobre formas de florescimento subjetivo e coletivo em circunstâncias de violência ou destruição política (e.g. LEAR, 2006; MAHMOOD, 2015; MAMDANI, 2014), daremos o nome a essa forma de resistência de 'esperança'. Diante dos atos de terrorismo no Benfica, que acompanham o recrudescimento da violência urbana em Fortaleza, os sujeitos com quem conversamos encaixaram suas respostas à violência num movimento rizomático ora em curso no Brasil de resistência e sobrevivência a violações de direitos humanos - visível, por exemplo, nas muitas manifestações em protesto ao assassinato da vereadora Marielle Franco.

\section{CENAS DE INTERLOCUÇÃO}

Entrevistar pessoas que foram vitimadas ou que se sentem ameaçadas por atos violentos é uma tarefa reconhecidamente delicada. Experiência desconcertante e destrutiva, a violência tende a desarticular ou interromper a fala. Em pesquisa de campo sobre a instalação das Unidades de Polícia Pacificadora (UPPs) nas favelas Santa Marta e Cidade de Deus, Palloma Menezes (2015) percebeu que uma dificuldade inicial de sua investigação era que "as pessoas sistematicamente evitavam ou se recusavam a falar sobre o fenômeno" (p.26). Falar de um evento amedrontador, em especial para alguém de fora, carregava consigo o potencial de mais violência no futuro - retaliação, por exemplo. Em face do medo da violência, 
os sujeitos de Menezes, muito frequentemente, rejeitavam um dos princípios fundamentais do uso da linguagem, o contrato de cooperação delineado por Grice (1967). Na concepção neo-kantiana de Grice, os/as usuários/as da língua racionalmente aderem ao princípio metapragmático da cooperação, i.e., visam ser mutuamente informativos; num eventual desencontro entre o que foi informado e o que foi implicitado, os/as usuários/as desvendam os enigmas enunciados por seus interlocutores recorrendo a máximas racionais que dizem respeito à verdade, à relevância, ao modo e à quantidade da informação, entendida como cooperativa e intencional. Instância de um momento em que a (iminência da) violência interrompe linguagem e cooperação, o excerto a seguir exemplifica o problema que Menezes (2015, p.28-19) enfrentou em seu campo:

\begin{abstract}
Na maior parte dessas atividades, assim como no cotidiano da favela, quase ninguém falava abertamente e de forma espontânea sobre as UPPs. E mesmo quando eu perguntava sobre o tema, tinha a sensação de que as pessoas preferiam mudar de assunto ou delicadamente apresentavam-me alguma desculpa para não falar sobre o tema. Isso apareceu de forma ainda mais enfática em uma das primeiras entrevistas que fiz no Santa Marta. Tal entrevista foi realizada com um morador de mais de 30 anos de idade com quem eu já havia conversado algumas vezes. No início da entrevista, tudo transcorria bem e ele até falava com bastante empolgação sobre a sua história de vida e algumas de suas percepções sobre a vida na favela. Ele chegou a comparar o Santa Marta com outras favelas, contando sobre uma namorada que morava no Morro da Providência (...). Aproveitei então a deixa da comparação dos morros para lhe perguntar se na época em que ele frequentava a Providência já tinha UPP no Santa Marta. Uma imediata mudança em seu semblante se impôs, o tom de voz também se alterou e o ritmo da conversa se perdeu. Toda empolgação foi abruptamente dissipada e, em um tom bastante enfático, o entrevistado respondeu: "sobre isso eu não falo, não gosto de falar sobre o tema".
\end{abstract}

Instâncias de silêncio ou recusa à fala como esta são recorrentes na literatura sobre violência (ver, por exemplo, LEVI, 1987; SCARRY, 1985; DAS, 2007). Partindo da premissa de que a violência tende a desarticular a linguagem - embora a linguagem também possa causar sua própria violência, como no caso do racismo e da fala do ódio -, nossa relação com os sujeitos que participaram desta pesquisa foi de uma interlocução que visava rearticular a experiência desorganizadora em outras bases. Assim, em Florianópolis, por Skype, Daniel Silva conversou com Malia Ixe, uma professora da UFC que teve um aluno ferido e organizou ato coletivo de luto na Praça da Gentilândia; na mesma praça, Claudiana Alencar e Daniel Silva organizaram um grupo focal em que entrevistaram Genaro Oliveira, indígena tapuyia kariri e estudante de filosofia na UECE, que estava na praça durante o atentado e sobreviveu, Otávio Martins, professor de filosofia da UECE, que também sobreviveu ao atentado, e Sam Siqueira, pastor evangélico e militante de direitos humanos; também participaram do grupo focal Jean Lopes, estudante da UFC que 
frequenta a praça, Diego Galeano, professor de história da PUC-Rio, e Natasha Carvalho, enfermeira. Tanto na entrevista por Skype quanto no grupo focal na Praça da Gentilândia nosso objetivo era escutar esses sujeitos e produzir, via diálogo, um relato sobre a cena de violência e sobre possibilidades de ação derivadas do trabalho de luto. Os sujeitos com quem conversamos sabiam que somos professores com trajetória de pesquisa no campo da violência; sabiam também de nosso engajamento político, de nossa relação de proximidade com aquele espaço da cidade e de nossa tristeza diante do que se passara. O luto, nesse sentido, era um afeto partilhado.

Um índice importante sobre a influência da agenda de entrevistadores em entrevistas que tematizem temas árduos como a violência emergiu em nossa reunião na Praça da Gentilândia. Era uma quarta-feira à noite, véspera do feriado prolongado de Páscoa. Estávamos de pé, com alguns dos sujeitos que comporiam o grupo focal, aguardando que os demais chegassem. Usualmente, a praça estaria repleta de frequentadores, sentados às mesas dos bares ou caminhando pelo local. Desde que o atentado ocorreu, no entanto, os bares não colocam mais mesas na praça; apenas algumas barracas que vendem comida e bebida não-alcóolica agora ficam abertas no local. $\mathrm{O}$ vazio causado pela ausência das muitas mesas de bares, aliado à presença ostensiva de policiais e de um posto móvel da PM, indiciavam o sentimento de que algum perigo estaria à espreita. Foi então que uma jornalista e um operador de câmera se aproximaram de nós, querendo que nossa fala fosse entextualizada - isto é, deslocada daquele contexto e recontextualizada em outro, tornando-se assim um "novo" texto (BAUMAN \& BRIGGS, 1990) - no telejornal do dia seguinte. As perguntas versariam sobre a questão da segurança no local depois do atentado. A reação unânime de todos nós, autores e sujeitos de pesquisa, foi de recusa ao pedido insistente da jornalista de nos entrevistar. O futuro aberto da entextualização é algo determinante para que alguém se recuse ou se disponha a falar sobre a violência. Num contexto de arranjos violentos, ter sua imagem divulgada na TV ou em mídias digitais e ter sua fala transformada, no movimento da entextualização, pode gerar riscos para os sujeitos - o que, em parte, explica o nosso silêncio.

Malia Ixe tematizou a questão do risco e do medo de falar sobre a violência com jornalistas naquele contexto particular. Ela conta que o ato de luto fora planejado para começar ao meio-dia da segunda-feira, 11 de março, dois dias depois do atentado. O planejamento do ato havia acontecido no domingo, via redes sociais e listas de e-mails da UFC. A imprensa ficou sabendo e, antes de os participantes chegarem ao local marcado, os jornalistas já estavam lá:

E já estava toda a imprensa, a televisão. Tava todo mundo lá né, esperando os alunos. Às $11 \mathrm{~h}$ da manhã. Então eles chegaram muito antes dos alunos, e depois chegaram os alunos, a gente 
se reuniu. E aí vieram conversar comigo: "Professora, a senhora que é a organizadora." E eu disse: "Eu não sou a organizadora." E depois eu vi que eles estavam muito aflitos né, e eram repórteres muito jovens. Aí eu fui lá conversar com eles e disse: "olha, gente, a gente não sabe do que se trata, a gente não sabe quem são as facções, a gente não sabe quem são as pessoas. A gente não sabe se elas estão aqui ou não. Então o que a gente faz de mais correto é não pegar o nome de ninguém, nem entrevistar ninguém, nem dizer quem foi organizador da ação. Vocês podem falar de uma maneira geral, alunos, professores, servidores, como a gente tinha colocado no e-mail né."

Embora a professora tenha escutado de especialistas em segurança pública que seria seguro realizar aquele ato de luto, o seu cuidado em não falar abertamente com jornalistas e em sugerir que eles não divulgassem o nome de participantes estava fundado em seu conhecimento de diferentes escalas do problema da segurança pública no Ceará. Sobre o contexto das ações do mundo do crime no estado, Malia Ixe traçou um panorama sobre a dinâmica do escoamento de drogas a partir do Ceará, um estado com localização geográfica, portos e aeroportos estratégicos para a distribuição de entorpecentes ilícitos para Europa e Estados Unidos. Esse mercado ilícito, que não se esgota no Ceará nem se encerra em seus trabalhadores locais, tem gerado disputas entre facções que não apenas visam controlá-lo mas também exterminar o grupo inimigo. Malia aponta que a GDE, uma "facção extremamente sanguinária", supostamente "é um braço do PCC" que busca "exterminar o Comando Vermelho". O derramamento de sangue e o ataque a "homens jovens de até 23, 24 anos" são o resultado, dentre outros fatores, da disputa por configurações locais desse mercado. Sobre o contexto das ações do mundo público, Malia criticou que o governo do estado "finge que está fazendo alguma coisa interessante, mas fica fazendo vista grossa para o que tá acontecendo. [O governador Camilo Santana] demorou muito para assumir que tinham facções criminosas controlando o estado". De fato, especialistas em segurança pública e violência urbana têm criticado o governo estadual por tentar mitigar a existência do crime organizado no estado. Luiz Fabio Paiva, pesquisador de sociologia da violência e professor da UFC, escreve que " o governo do estado, em seu discurso público, declarava que falar de facções no Ceará 'era brincadeira'" (PAIVA, 2018, s/p). Ainda segundo Malia, as próprias instituições do mundo público não conseguem lidar adequadamente com a dinâmica do mundo do crime num dos sítios de sua articulação e tomada de decisões, os presídios. A professora conta que a secretária de justiça do Estado, Socorro França, mostrou-lhe despachos em que juízes do interior libertam pessoas presas que se autodeclararem faccionadas "porque não têm um aparato de segurança para manter uma pessoa faccionada presa". A interação de Ixe com a secretária de justiça no mínimo adiciona uma camada de complexidade à situação descrita por Luiz Fabio Paiva: segundo o sociólogo, após a "guerra entre facções" ter sido declarada - isto 
é, após a "pacificação" de 2015-2016 - "os presídios cearenses foram reordenados para que cada unidade correspondesse a uma facção criminosa específica."

Nesse sentido, para Malia Ixe, no plano macropolítico, convive-se no Ceará "com um estado paralelo, que a gente ouvia falar mas que a gente tá vendo acontecer agora". Em várias dimensões, esse estado paralelo coincide com a hipótese aludida acima da coexistência e disputa entre os regimes normativos de crime e de governo. Nesse plano macropolítico, a desigualdade gera territórios "em que a justiça não existe nesse instante. E os territórios não são territórios nacionais (...), eles são do crime." No plano micropolítico, Malia destaca que "isso chegou a todos (...), todas as pessoas conhecem as regras do crime". Ela conta que Labélia, uma mulher trans que mora na periferia de Fortaleza, contou a ela durante um festival de cinema em que ambas foram juradas que não pode mais usar cabelo vermelho em seu bairro. Pessoas ligadas a um grupo rival do Comando Vermelho a intimidaram dizendo que se ela queria "permanecer viva" seria "melhor mudar a cor do cabelo." Em escala micropolítica, assim, "as pessoas estão agindo em função dessas regras".

A articulação tensa desses planos provocou em Malia Ixe sentimentos diferentes no contexto do atentado: choque, pela vitimação de um de seus alunos, que foi internado em consequência de um tiro na cabeça; medo, "por causa de tudo isso que eu já conheço", isto é, os arranjos violentos por ela narrados; raiva, pela ineficiência da justiça em proteger defensores de direitos humanos, como Marielle Franco, cujos assassinos (aparentemente pertencentes tanto à câmara dos vereadores quanto às milícias, i.e., ao mundo público e ao mundo do crime) ainda não foram identificados pelo sistema de justiça do mundo público.

Esses sentimentos geram silêncio em certas cenas de interlocução, mas também podem ser propulsores de um movimento de rearticular condições de fala e sociabilidade que foram fragmentadas. Luiz Paulo da Moita Lopes escreve que pesquisadores da linguística aplicada, campo em que este trabalho se inscreve, têm tentado "criar inteligibilidade sobre problemas sociais em que a linguagem tem um papel central" (2008, p.14, grifo do autor). De fato, o que tornou aquelas entrevistas e o presente relato possíveis foi a tentativa partilhada pelos autores e seus interlocutores no campo de criar inteligibilidade sobre um problema que tem afetado a todos.

\section{FIGURA: A PRODUÇÃO DA SOBREVIVÊNCIA E DA ESPERANÇA}

Uma questão premente do mundo contemporâneo, já formulada em alguns estudos sociais e linguísticos, pode ser enunciada da seguinte forma: Como as pessoas fazem para sobreviver como indivíduos e comunidades a despeito da violência e da 
tentativa de aniquilação a que são submetidos? O filósofo Jonathan Lear (2006) chamou de 'esperança' o afeto que pode emergir quando uma forma de vida inteira é aniquilada. Ele ancora seu debate sobre esperança na história dos indígenas Crow, uma tribo nômade que vivia ao longo do rio Yellowstone e que, no século XIX, foi confinada em uma reserva pelo governo americano. As formas de vida dos índios Crow, baseadas na cultura e nos rituais da vida nômade, foram, em certa medida, destruídas pela violência do confinamento. Lear aborda essa questão com base no relato que Plenty Coups, o líder da etnia Crow, oferece a Frank B. Linderman, um "homem branco" que entextualiza sua biografia para a forma escrita². Plenty Coups metonimicamente verte a aniquilação do modo tradicional de vida dos Crow em termos da partida do búfalo:

Plenty Coups recusou-se a falar de sua vida depois da passagem do búfalo, de modo que sua história parece ter sido fissurada, tornando muitos anos inenarráveis. "Eu não the contei ainda metade do que aconteceu comigo quando eu era jovem", ele me disse, urgindo que eu seguisse com minha escuta. "Acho que posso ainda lembrar mais e contar mais coisas sobre guerra e roubo de cavalos. Mas quando o búfalo partiu os corações do meu povo caíram no chão, e eles não conseguiram mais levantá-los. Depois disso, nada aconteceu. Passou a ter pouco canto nos lugares. Além disso," ele acrescentou pesaroso, "você conhece essa parte da minha vida tão bem quanto eu. Você sabe o que se passou conosco quando o búfalo partiu." (LINDERMAN, 1962, apud LEAR, 2006, p. 2)

Para Lear, o enunciado "Depois disso, nada aconteceu" indica a devastação de todo o modo de vida [way of life] de uma cultura. Cantar não fazia mais sentido, nem vestir-se ritualmente para lutar contra a Nação Sioux, a tribo tradicionalmente inimiga dos Crow. O confinamento em uma reserva foi violento na medida em que destruiu todo o universo de referência — a vida nômade - a partir do qual os signos da cultura Crow faziam sentido. Embora índices como "os corações caíram no chão" ou "pesaroso" possam sugerir no multi-nivelamento de vozes dessa citação que Plenty Coup e os Crow tenham entrado num estado de melancolia que os impediu de falar sobre o que veio depois da partida do búfalo, Lear colhe evidências em toda a narrativa e no desdobrar da vida Crow que demonstram a elaboração de uma "esperança radical" entre os indígenas. Por exemplo, um sonho que Plenty Coups teve ainda jovem foi coletivamente interpretado de forma profética pelos Crows como forma de "enfrentar um futuro radicalmente diferente" (p. 68). Lear se diz fascinado pela forma como, especialmente naquele

2. Lear usa 'white man' e 'Indians' no livro em função da preferência dos Crow por esses termos. Considerados ofensivos no espaço público estadunidense, os termos são aparentemente ressignificados pelos Crow. Linderman já mantinha contato por cerca de 40 anos com os Crows quando verteu o relato de Plenty Coups. A relação de confiança entre os dois é uma das razões pelas quais o líder Crow confia-lhe sua narrativa oral. 
momento, "os Crow usaram os sonhos cooperativamente" (p. 71). Jovens eram estimulados a sonhar, e os mais velhos, no ritual coletivo de narração dos sonhos, ofereciam sua interpretação.

Nos termos de Lear, esse trabalho colaborativo de interpretação da tribo imbuiu na ontologia Crow a "confiança de que eles iriam sobreviver" (p. 104). O cultivo de formas éticas de viver como um Crow foi fundamental para que o grupo criasse uma esperança radical:

os Crow cultivaram esperança na emergência de uma subjetividade que ainda não existia. Haveria formas de continuar a se formar como um sujeito Crow — formas de florescer como Crow - embora as formas tradicionais tivessem sido destruídas. Essa esperança é radical na medida em que ela se direcionava a uma subjetividade que, ao mesmo tempo, é Crow e não existe ainda (LEAR, 2006, p. 104).

Para os Crow, era preciso confiar na emergência de uma nova forma de ser um Crow que ainda não existia. Em meio à devastação, os Crow tiveram de imaginar um novo "alcance discursivo e metadiscursivo da 'esperança" (CRAPANZANO, 2003, p. 4) para continuarem fazendo sentido de sua experiência. O cultivo de formas éticas de se formar como um sujeito Crow, além da reinvenção de regimes metapragmáticos da esperança (como o ritual colaborativo de interpretar sonhos), foram necessários para a sobrevivência Crow. Com base nesse relato e na ainda exígua produção acadêmica sobre o tema, 'esperança' é aqui entendida como o trabalho semiolinguístico em que as pessoas se opõem à violência e à destruição com alguma construção coletiva de uma perspectiva de sobrevivência (BLOCH, 1996; CRAPANZANO, 2003; MIYAZAKI, 2004, 2006; MAHMOOD, 2016).

'Como é que se sobrevive a isso [isto é, à destruição ocasionada pelo atentado]?' foi uma pergunta que fizemos aos sujeitos que, de diferentes modos, tiveram sua experiência fraturada pelo acontecimento. Dedicaremos o restante deste relato a delinear as formas que a esperança assumiu naquelas interações.

\subsection{Espaçamento da violência; espaços da esperança}

Genaro Oliveira e Otávio Martins estavam na Praça da Gentilândia quando os dois atiradores desceram do carro e iniciaram uma longa sequência de tiros contra as pessoas que estavam ali sentadas. Segundo Otávio, havia "tranquilamente entre 500 e 600 pessoas" na praça. Eles nos contaram detalhes da cena em que alvos aparentemente predeterminados eram atingidos juntamente com outras pessoas no local. Este é um trecho do grupo focal em que eles conversam sobre o atentado: 


$\begin{array}{lll}1 & \text { Genaro } & \text { Chegaram atirando daquela parede lá. } \\ 2 & \text { Claudiana } & \text { Vieram atirando lá? Chegaram atirando? } \\ 3 & \text { Genaro } & \text { Desceram, mataram o primeiro bem ali, aí depois } \\ 4 & & \text { mataram outro aqui, depois voltaram pra matar outro } \\ 5 & & \text { ali na frente. E enquanto isso o tiro rolando. Aí teve o } \\ 6 & & \text { rapaz do francês, né, que teve o tiro na cabeça e ficou } \\ 7 & & \text { ali. Teve uma moça que trabalhava ali no bar que } \\ 8 & & \text { também ficou no chão } \\ 9 & \text { Otávio } & \text { Foi surreal. } \\ 10 & \text { Genaro } & \text { Sem falar no pessoal que foi passando por debaixo das } \\ 11 & & \text { mesas, derrubando tudo, cadeira, tudo que é copo, } \\ 12 & & \text { gritaria } \\ 13 & \text { Otávio } & \text { copo } \\ 14 & \text { Claudiana } & \text { Gritavam? } \\ 15 & \text { Otávio } & \text { Sim. Gritavam, o tempo todo. }\end{array}$

Uma noção de excesso marcou o relato dos dois sobreviventes. Como lemos acima, na sequência da descrição de Genaro (linhas 1-8), que explica a Claudiana como os assassinos abordaram as vítimas, Otávio nomeia de "surreal" o acontecido. Genaro nos disse já ter presenciado o assassinato de amigos em seu bairro, mas a escala do uso da força e da matança naquela cena foi algo por ele nunca antes visto: "Lá na Bela Vista eu já tinha visto alguma coisa parecida, mas desse jeito aqui, de o cara chegar atirando, atirando, atirando, eu nunca tinha visto," comentou o jovem em outro trecho da entrevista. Conceito-limite, a violência tende a romper a significação, atirando os sujeitos para além dos limites do que pode ser explicado e, portanto, compreendido (ver, por exemplo, SILVA, 2017; SCARRY, 1985). O filósofo Jean-Luc Nancy (2005) afirma que a violência destrói e desorganiza o significado daquilo que ela ataca. Vejamos o excerto a seguir:

A violência não transforma aquilo que ela ataca; ao contrário, ela expropria sua forma e significado. Ela torna seu objeto nada mais do que um signo de sua própria fúria, uma coisa ou ser atacado ou violado: uma coisa ou ser cuja essência mesma agora consiste em ter sido atacado ou violado. De outro lugar ou de um além, a violência empunha outra forma, quiçá outro significado (NANCY, 2005, p. 16).

Esse excerto merece atenção, porque ele articula pontos importantes dos arranjos violentos e da esperança que emerge como resistência a eles. Primeiro, Nancy aponta que a violência tende a interromper o alvo de seu ataque: "ela torna o objeto [do ataque] um signo de sua própria fúria." Depois, Nancy fala de um 
"outro lugar ou de um além" em que a violência "empunha outra forma, quiçá outro significado". É como se o espaço da violência tivesse duas camadas: uma delas - um "não-lugar" - é pura destruição; a outra - um "outro lugar" ou "além" - empunha outra forma e significado, i.e., significa em seus próprios termos. Essa dupla camada topológica pode ser lida no seguinte comentário de Otávio: "Era pra ser violento. Era pra ser excessivamente violento. Era pra assustar. Era pra mandar uma mensagem, entendeu?" Otávio articula o "não-lugar" embutido na extrapolação de limites do atentado - "era pra ser excessivamente violento", "era pra assustar" com o significado que emerge do "outro lugar" ou do "além" da violência: "era pra mandar uma mensagem". Assim, a violência daquele atentado, articulada nos termos de uma pragmática mais geral da violência, a um só tempo extrapolou limites de entendimento e impôs sua própria significação, mandou sua própria mensagem. Mas assim como Plenty Coups desviou a atenção de seu interlocutor para além dos anos inenarráveis depois da partida do búfalo, focando então nas histórias de sua juventude, na guerra e no roubo de cavalos anteriores à destruição da forma de vida coletiva dos Crow, os sujeitos com quem dialogamos ressignificaram esse "outro lugar ou além" de onde a violência manda sua própria mensagem. Depois da destruição, outras coisas podem ser ditas, apesar da eloquência da violência e sua própria mensagem. E foi isso o que nossos interlocutores fizeram.

\subsection{A gente tá ocupando menos essa cidade. Vou ocupar mais.}

Tendo partido o búfalo, Plenty Coups falou de como os Crow se reinventaram como indígenas Crow, redimensionando a temporalidade da sua ação - por exemplo, se recusando a falar do que aconteceu depois da passagem do búfalo -, bem como os regimes discursivos e metadiscursivos dessa reinvenção, chamada por Lear de 'esperança radical'. Tendo se deparado na Praça da Gentilândia com um arranjo violento do mundo do crime e com o jogo de forças deste com o mundo público, Genaro eloquentemente narrou sua forma de habitar a esperança.

Para nós, é impressionante a similaridade entre os termos da esperança no relato de Genaro e no trabalho de Ernst Bloch, filósofo alemão que, de forma pioneira, propôs uma reflexão marxista sobre o afeto da esperança. Genaro inicialmente nos contou que, "depois desse negócio [o atentado], eu comecei a pensar assim, cara, a gente tá ocupando menos essa cidade. Vou ocupar mais. Então eu tenho saído mais de bicicleta, por incrível que pareça. Eu tenho ido a outros bairros que antes eu não frequentava. Tenho andado mais, conhecido mais gente." Assim, em vez de se recolher e se privar da cidade - tendência que Caldeira (2000) observa em São Paulo como resultado do crescimento do crime urbano e da segregação do 
espaço, produtora de enclaves fortificados privados e do abandono de espaços públicos -, Genaro explica que passou a "ocupar mais" a cidade, circulando por bairros que não frequentava e tentando conhecer pessoas. Para Bloch (1986), a esperança é uma forma de sonhar acordado que nos impulsiona adiante. Esse sonho acordado, diz Bloch, libera nosso inconsciente 'para cima' e 'para frente', para o Ainda-Não-Consciente do sonhar acordado. Genaro decide ir adiante em vez de se confinar, insiste também em resistir - a despeito do atentado que testemunhou e da criminalização de seus espaços de sociabilidade, como a aldeia indígena de seu povo no interior do estado e o bairro periférico em que vive em Fortaleza, Bela Vista.

Coincidindo com o que Bloch narrou em registro filosófico, Genaro aponta que a direcionalidade do afeto da esperança é não só para frente, mas também para o outro. Escreveu Bloch: "A esperança gesticula ativamente para além do indivíduo." Para o filósofo, a esperança é participativa e ensinável, sendo portanto "maior do que o indivíduo", fazendo-o "expandir em vez de confinar-se" (1986, p. 3). Genaro, por seu turno, aponta que sua esperança não é individual, mas coletiva. Identificandose como indígena e reconhecendo a violência que seu povo tem historicamente sofrido, ele diz: "De uns tempos pra cá a população indígena tem crescido. Pra mim isso é um sintoma de esperança. A gente é muito mais hoje do que era na ditadura. Éramos 700 mil, hoje quase 1 milhão. Esse povo tá pipocando por aí, tá nascendo, tá crescendo, tá resistindo." O Eu que resiste à violência - que tem esperança - é assim projetado para outras escalas. Uma dessas escalas é a perspectiva do sofrimento e resistência indígenas: assim como cresce sua circulação na cidade, seu povo resiste e cresce. Outra escala em que Genaro projeta sua esperança é a sobrevivência na favela. (Daniel havia trazido para o grupo focal um relato de Raphael Calazans, jovem morador do Complexo do Alemão, que contou ao pesquisador e ao grupo de pesquisa de que participa no Rio de Janeiro que a cultura na favela é uma cultura de sobrevivência: uma forma de solidariedade e irmandade que resiste à opressão, às condições de precariedade e à criminalização de setores do mundo público - ver, por exemplo, FACINA, 2014). Assim, o jovem tapuyia kariri, que vive num espaço periférico em Fortaleza, se identifica também com a cultura de sobrevivência na favela, expandindo ainda mais a dimensão de seu estar e agir no mundo. Eis o excerto em que Genaro vai elaborando, conosco, as escalas de sua identificação como indígena e favelado: 


\begin{tabular}{|c|c|c|}
\hline 1 & Genaro & (...) eu venho de duas culturas né. Fui criado tanto no interior de \\
\hline 2 & & São Benedito, com meus parentes indígenas. Como fui criado \\
\hline 3 & & aqui na Bela Vista. Então eu tenho digamos assim... \\
\hline 4 & Claudiana & Ele é tapuyia kariri, é parente nosso. \\
\hline 5 & Genaro & Lá de São Benedito. Essa ideia que ele falou do rapaz no Rio né. \\
\hline 6 & & Disse que é uma cultura né.. \\
\hline 7 & Daniel & ... Cultura de sobrevivência \\
\hline 8 & Genaro & Cultura de sobrevivência. E essa história de o estado estar \\
\hline 9 & & oprimindo tanto um quanto o outro, eu venho dessas duas \\
\hline 10 & & questões. Lá a gente luta tanto pela terra quanto/ a gente é \\
\hline 11 & & colocado à margem. É índio, é não sei o quê. É o brasileiro, \\
\hline 12 & & cidadão, que por mais que tenha sangue indígena não se vê índio. \\
\hline 13 & & E aqui também o cidadão de bem contra a pessoa da favela. \\
\hline 14 & & [[interrupção] $]$ \\
\hline 15 & & Pois é, é isso. Eu procuro não deixar o medo tomar conta de \\
\hline 16 & & mim. O medo existe. Mas eu não deixo o medo me paralisar. \\
\hline 17 & & Dentro da própria Universidade Estadual do Ceara apontaram \\
\hline 18 & & uma arma pra mim, no dia da Semana Universitária. Estávamos \\
\hline 19 & & sentados em frente ao bloco L, conversando. Chegam 4 rapazes, \\
\hline 20 & & dizendo que são policiais, à paisana, perguntando por que a gente \\
\hline 21 & & estava ali. Perguntando cadê as drogas. Que nem a música do \\
\hline 22 & & Bezerra né, "não tem flagrante porque a fumaça subiu" E aí \\
\hline 23 & & foram muito truculentos com a gente, deram um tapa na cara de \\
\hline 24 & & um amigo nosso. Aí eu voei em cima do cara. Quando eu voei \\
\hline 25 & & em cima do cara ele puxou a arma pra mim. E aí eu comecei a \\
\hline 26 & & gritar: 'Atira, no meio da universidade, em mim. Pode atirar, \\
\hline 27 & & mata'. E todos os professores, que tavam acontecendo nas salas \\
\hline 28 & & apresentação de trabalhos. Teve uma professora que olhou e \\
\hline 29 & & falou: 'falem mais baixo aí que o fulano tá apresentando \\
\hline 30 & & trabalho'. Eu olhei e falei: 'minha senhora, você não tá vendo \\
\hline 31 & & que esse cara tá apontando uma arma pra mim não?’ Um outro \\
\hline 32 & & professor de filosofia, olhou, e nem pra dizer: 'olha, é meu aluno. \\
\hline 33 & & É, meu aluno', nem pra dizer isso. \\
\hline
\end{tabular}

O fato de o relato ter sido produzido coletivamente, no mesmo espaço onde menos de um mês antes acontecera o atentado que poderia tê-lo vitimado, não é trivial. Algumas camadas de complexidade dessa narrativa decorrem disso. 
Como a psicanálise e as comissões de verdade e reconciliação têm demonstrado, narrar um episódio violento, em certas condições enunciativas, pode ser uma forma performativa de rearticular uma fratura do passado (VERAS, 2011). Por exemplo, uma pessoa que relata, em sessão psicanalítica, um episódio ofensivo por ela sofrido pode, ao recontextualizar o ato injurioso para um interlocutor investido de autoridade simbólica - isto é, um/a analista com quem se estabeleceu uma relação de transferência -, ressignificar a cena violenta. Pode, em outras palavras, passar a habitar a situação de injúria de outra forma, rearticular sua forma de lidar com o espaço e o tempo da ofensa, delinear uma capacidade para agir. Habitar de outra forma o espaço e o tempo da violência - ou melhor, espaço e tempo projetados como violentos - parece ser a reivindicação de Genaro no excerto acima. Estávamos sentados no mesmo espaço onde duas semanas antes o atentado havia ocorrido. Falar de sobrevivência, naquela praça, já era uma forma de ressignificar o modo de habitá-la: não mais o lugar do medo ou da morte, mas o lugar da esperança.

Assim, nesse contexto de ressignificação, entre as linhas 1 e 3, Genaro se identifica tanto com grupos minoritarizados indígenas quanto com moradores das periferias de Fortaleza. (Claudiana também se identifica com seu pertencimento indígena, projetando-o como parente "nosso", o que indicia o caráter coletivo das identificações naquela cena de interlocução). Ele então contesta o estigma e a criminalização a que esses dois grupos são submetidos, articulando ambos, o estigma e a criminalização, nos termos do conceito de cultura de sobrevivência que Daniel havia trazido para a conversa (ver FACINA, 2014; SILVA; FACINA; LOPES, 2015). A sobrevivência é um tropo identificável nas mais diversas formas de resistência de grupos subalternizados. Nos termos de Derrida, "o sobreviver transborda, ao mesmo tempo, o viver e o morrer, suplementando-os, um e outro, com um sobressalto e um certo alívio temporário, parando a morte e a vida ao mesmo tempo" (Derrida, 2004, p. 89). Entre as linhas 17 e 33, Genaro demonstra que, naquela interação com policiais, o intervalo entre viver e morrer era tênue - o que, no entanto, não o impede de sobreviver. Se, por um lado, a ação dos policiais excede os discursos da vida que fundam o estado democrático de direito (na medida em que eles estavam abordando alguém sem mandado de segurança, num território autônomo onde a ação da polícia deve ser restrita), Genaro, por outro lado, desafia esses mesmos discursos da vida dizendo para o policial: "Atira, no meio da universidade, em mim. Pode atirar, mata." Suspendendo a vida e a morte, Genaro sobrevive: seus imperativos 'atira' e 'mata' são sequencialmente acompanhados de questionamentos da própria legitimidade da ação policial (linha 26: "no meio da 
universidade") e da banalização da cena de violência (linhas 29 e 30: uma professora diz, "falem mais baixo aí que o fulano tá apresentando trabalho").

$\mathrm{O}$ relato de Genaro, situado numa cena interativa que buscava resistir aos arranjos violentos do mundo público e do mundo do crime, é agentivo. $\mathrm{O}$ jovem tapuya kariri diz que o "medo existe", mas não "deixa o medo [lhe] paralisar." Ele não se deixa paralisar nem pelo atentado do crime na praça, nem pela repressão da polícia no campus da universidade, respondendo que vai ocupar mais a cidade. Vai, em outras palavras, ocupar o território da esperança, esse afeto que faz os sujeitos sonharem acordados, a despeito da tentativa de seu aniquilamento.

\subsection{A gente tem que tomar cuidado com as narrativas}

O último excerto do grupo focal na Praça da Gentilândia que iremos comentar aponta para a camada metapragmática da esperança. Michael Silverstein (1976), a partir de um insight de seu orientador, Roman Jakobson, propôs que todo uso da linguagem pressupõe algum tipo de imaginação sobre sua forma, função, circulação... - um tipo de conhecimento meta, ou sobre, que, apesar de não igualmente distribuído entre falantes, afeta o próprio uso linguístico. Tratase, em outras palavras, da função metapragmática da linguagem, um domínio de imaginação sobre usos linguísticos que anda lado a lado com a pragmática ou uso da linguagem. Nas interações de que participamos para a realização deste estudo, a função metapragmática preponderante era aquela do regime normativo dos direitos humanos (ver, por exemplo, MESQUITA NETO, 2008). Tanto Malia Ixe quanto Sam Siqueira e os dois sobreviventes do atentado encaixavam a pragmática de seu discurso numa metapragmática mais geral da linguagem dos direitos humanos. Na nossa opinião, esta foi uma das formas em que a esperança emergiu naqueles encontros, na medida em que o regime normativo dos direitos humanos justifica a motivação, a manutenção e a proteção da vida humana no território dos direitos e não no espaço da vingança ou da violência. No restante deste artigo, comentaremos dois momentos em que, de forma explícita, Sam e Malia ajustaram a interação para o domínio metapragmático da esperança. Observemos inicialmente a posição de Sam Siqueira.

Enquanto conversávamos sentados na Praça da Gentilândia, Natasha Carvalho reuniu-se a nós. Como o encontro era informal, Daniel aproveitou para convidá-la a participar do grupo, já que ela também tinha interesse em conversar sobre o atentado. A conversa já transcorria há um tempo e, com sua chegada, Daniel a atualizou do que havia sido discutido. Na sua familiarização com o assunto, 
Natasha perguntou: "Mas [o atentado era direcionado a] eles, ou eram inocentes, pessoas que não tinham nada a ver?"

A maioria das pessoas na mesa tentou explicar que, aparentemente, havia alguns alvos predestinados, mas que os tiros foram desferidos também contra pessoas que não participaram dos arranjos e articulações do mundo do crime. Sam Siqueira, no entanto, provocou uma ruptura nessas explicações, pontuando o seguinte: "Eu acho que a gente precisa, uma coisa que eu tenho colocado muita energia, falado com muitas igrejas, de todos os âmbitos, muitas escolas. A explicação para o homicídio não pode ser o envolvimento." Diego e Jean imediatamente concordaram, e Sam continuou: "É como se a gente legitimasse que algumas pessoas podem morrer e outras não. Ninguém pode morrer." Sam, portanto, estava ajustando a interação para o regime metapragmático dos direitos humanos. Como se lê no Artigo $3^{\circ} \mathrm{da}$ Declaração Universal dos Direitos Humanos: "Todo indivíduo tem direito à vida, à liberdade e à segurança pessoal."

Militante de direitos humanos, Sam se opôs assim à deslegitimação dos direitos humanos que grassa no mundo público brasileiro. A cobertura jornalística do atentado terrorista - ou chacina, como se designou amplamente o assassinato coletivo - foi amplamente ancorada na justificação que Sam buscou contestar. A seguir, transcrevemos os $1 \mathrm{~min} 13 \mathrm{seg}$ iniciais da cobertura ao vivo realizada pela Tribuna do Ceará do ato de luto organizado por Malia Ixe e outros professores da UFC:

\begin{abstract}
Olá, leitores do Tribuna do Ceará, voltamos mais uma vez ao vivo, acompanhando aqui a manifestação de luto em relação à chacina do Benfica. Vocês podem perceber, os manifestantes eles estão indo em direção à Praça da Gentilândia, um dos locais onde algumas vítimas morreram. Eles pararam o trânsito para que alguns manifestantes pudessem atravessar a avenida aqui 13 de Maio sem maiores complicações. Como vocês podem ver, eles estão aqui se aglomerando na Praça da Gentilândia. Lembrando que aqui foi um dos pontos onde as vítimas da chacina morreram, né? Foi o primeiro registro de homicídio na sexta-feira à noite. Já chegando a madrugada pelo sábado. As vítimas da chacina foram três... é... sete pessoas, três tinham passagem pela polícia. José Gilmar Furtado de Oliveira Júnior, 33 anos, ele tinha passagem pela polícia por roubo e posse de drogas. Antonio Igor Moreira Silva, de 26 anos, tinha passagem pela polícia por posse de drogas também. E também Pedro Braga Barroso Neto, duas passagens pela polícia por roubo e por associação criminosa. Os restantes não tinham nenhuma passagem pela polícia nem antecedentes criminais, que foram um total de quatro (...) (TRIBUNA DO CEARÁ, 2018).
\end{abstract}

Perceba-se que, já na abertura da narração do evento, ter passagem pela polícia é um critério de classificação das vítimas do atentado. Esse modo de narrar as mortes foi recorrente nas reportagens que lemos sobre o assassinato coletivo. Nos termos de Sam e da linguagem dos direitos humanos de forma mais ampla, descrever vítimas letais da violência como pessoas "que têm envolvimento" ou "que têm passagem pela polícia" é um modo de hierarquizar vidas e de, implicitamente, justificar que 
essas vidas valem menos e portanto não merecem ser vividas (BUTLER, 2005). Sam veementemente contestou essa hierarquização e justificação, apontando que devemos ser éticos com as palavras. Eis o seu comentário metapragmático: "Ninguém pode morrer. E a gente tem que tomar cuidado com as narrativas." Natasha demonstrou ter aprendido (ou concordado) com a metapragmática explícita de Sam, respondendo que "é seletivo, né? Eles fazem uma seleção."

Nitidamente tocado pelo problema da hierarquização de vidas em discursos criminalizadores das periferias, Sam apresenta uma camada afetiva do problema, articulando a dor de mães que veem seus filhos hierarquizados e a dor de Deus ao perder seu filho:

A maior dor das mães das vítimas do Curió era quando saía na televisão dizendo que o filho
delas era envolvido. Ninguém tinha envolvimento com crime nenhum. E a televisão, os
programas policiais disseram. Aí você imagina uma mãe, que perdeu um filho. Eu acho que
a maior tragédia do mundo é você perder um filho. É a dor de Deus né. Na minha religião é
a dor de Deus. Deus perdeu um filho, né? (...) Aí a criatura perde um filho e ainda tem um
linchamento social do filho. Ninguém merece passar por isso. Ninguém. Eu já conheci gente
muito perversa. Se é que se pode dizer que um ser humano pode ser perverso? Pode. Mas
quando você vai falar com a mãe ela diz: 'é meu filho'. Ela não diz, 'não, é o meu bandido'. (...)

Sam invoca portanto religião e parentesco para articular sua defesa dos direitos humanos. Ele foi enfático em dizer que, em sua atuação em presídios, aprendeu que "nenhum ser humano é aquilo". Isto é, para Sam, a figura do humano não pode ser colada à figura do criminoso, porque "crime", segundo o pastor e militante de direitos humanos, é um problema social com uma matriz social complexa; para ele, explicar a criminalidade não pode prescindir da análise de padrões mais gerais de desigualdade, oportunidades de canalização da energia vital (p.ex., através do esporte ou emprego) e violência estrutural que diferencialmente estruturam a topografia das cidades brasileiras.

Naquela interação, portanto, ter esperança era também uma questão de usar as palavras eticamente, nos termos dos direitos humanos e da justiça social. Como há mais de meio século defendeu John L. Austin (1962), palavras são ações, e seus efeitos, embora não plenamente sob controle de quem as enuncia, afetam a vida social.

\section{CONSIDERAÇÕES FINAIS}

Finalmente, gostaríamos de retomar a interação de Malia Ixe com Daniel Silva por Skype, para discutir outras nuances disso que temos chamado de 'metapragmática da esperança'. Embora a professora apontasse um pano de 
fundo "inóspito" nos setores de classe média de Fortaleza bem como descrevesse com precisão microscópica as estatísticas do crime violento na cidade, seu posicionamento sempre escapava desse quadro geral. O comentário sobre o caráter hostil dos setores de classe média surgiu no contexto de comentários sobre medidas de cautela e precaução na circulação pela cidade. Malia Ixe falou do caráter inóspito que têm se tornado alguns espaços de classe média - etnograficamente, Caldeira (2000) percebe a construção simbólica de "muros" em torno desses espaços, isto é, a produção arquitetônica de enclaves fortificados nas cidades brasileiras, como shopping centers e condomínios fechados, bem como a produção discursiva de regimes de circulação da fala nesses espaços, fortemente baseados na "fala do crime". Malia disse que seu filho, adolescente, estuda num colégio de classe média alta "e a circulação dele [termina sendo] no meio de pessoas idiotas. Porque esses caras com discurso de Bolsonaro, ou falando mal da Marielle na sala dele. Ele disse que são mais de $50 \%$. Então é assim um ambiente inóspito, né? O Brasil se torna um ambiente inóspito. Porque você não tem diálogo com as pessoas. E é muito ruim não ter diálogo."

A adesão ao discurso de desrespeito aos direitos humanos de Jair Bolsonaro e as críticas à vereadora Marielle Franco, assassinada por sua defesa desses direitos, indiciam algumas fronteiras no Brasil contemporâneo (têm sido notórios, por exemplo, a polarização política e o acirramento do ódio na fala cotidiana). Apesar do delineamento dessas fronteiras, a professora continuamente aderia à metapragmática da esperança, que transborda essas circunscrições. Um exemplo disso é a resposta que Malia dá ao comentário de Daniel: "é como se Fortaleza tivesse se tornado um lugar mais triste para se viver." Segundo a professora, "é e não é, né? A gente tem coisas maravilhosas." Fugindo da lógica da não-contradição, para Malia não é possível classificar Fortaleza dentro de fronteiras definidas - é possível, afinal, imaginar a cidade de outra forma. O segundo exemplo da adesão ao regime metadiscursivo da esperança vem de sua resposta à pergunta feita sobre o perfil do "criminoso" no atual contexto dos arranjos violentos no Ceará. Daniel havia perguntado de modo genérico - "para você, quem é o criminoso?" - e a resposta então foi formulada por Malia Ixe de acordo com sua macrodescrição do comércio ilícito de drogas. Para ela,

não é um criminoso, né? São vários perfis de criminosos. Mas o que eu penso sinceramente, criminoso é aquele que aceita o container de drogas lá na Holanda, né? Criminoso é o porto ou aeroporto lá nos Estados Unidos que aceitam a droga entrar. Porque se eles não aceitassem a droga, a gente não enviava. $\mathrm{O}$ grande criminoso é quem aceita a droga que sai daqui. (...) Eu não sei, quando você pergunta assim quem é o criminoso, são muitas faces. Com certeza não é a pessoa que tá na ponta com a metralhadora na mão. Não é esse cara. Esse cara é vitima. 
Esse cara que tá com a metralhadora na mão matando a mando é tão vítima quanto a gente. $\mathrm{O}$ criminoso é outro e esse criminoso tá muito bem guardado, né?

Mais uma vez, portanto, a professora invocou o cenário macro do mercado transnacional ilícito de drogas, do qual o mundo do crime no Ceará participa como importante bub (e não sem a conivência de alguns atores do mundo público). Para Malia, entender agência e responsabilidade nesse mercado, bem como a tipificação de "crime", implica uma discussão mais aprofundada das desigualdades que estruturam a sociedade brasileira.

Para finalizar, gostaríamos de apontar que essa metapragmática da esperança, nos relatos sobreviventes que apresentamos neste artigo, é algo intercambiável com 'metapragmática dos direitos humanos', na medida em que ter esperança, naqueles diálogos, significou responder à violência que feriu a estrutura de afetos dos participantes não por meio de vingança ou de mecanismos extralegais ou excepcionais de violência reativa mas por meio de tropos que informam a defesa dos direitos humanos. Seja pela propensão a ocupar mais o espaço público, pela contestação de hierarquizações de vidas ou pelo desafio a fronteiras do Brasil contemporâneo, os sujeitos com quem conversamos resistiram à violência imaginando outra forma de viver coletivamente.

\section{REFERÊNCIAS}

AUSTIN, J. L. (1962) How to do things with words. Oxford: Oxford University Press.

BARROS, J., PAIVA, L., RODRIGUES, J., SILVA, D. B.; SANTOS, L. (2018) "Pacificação" nas periferias; discursos sobre as violências e o cotidiano de juventudes em Fortaleza. Revista de Psicologia, n.9 v.1, pp.117-128.

BAUMAN, R; BRIGGS, C. (1990) Poética e performance como perspectivas críticas sobre linguagem e a vida social. Tradução de Vânia Cardoso. Ilha - Revista de Antropologia, n. 8, v.1, 1990, pp. 185-229.

BIONDI, K. (2014) Junto e misturado: uma etnografia do PCC. São Paulo: Terceiro Nome.

BLOCH, E. (1986) The principle of hope. Cambridge: MIT Press.

BUTLER, J. (2011) Vida precária. Contemporânea, UFSCAR, n.1, p.13-33.

CALDEIRA, T. (2000) City of Walls: Crime, Segregation and Citizenship in São Paulo. Berkeley: University of California Press. 
CAVALCANTE, I. (2018) Veja tudo o que se sabe até agora sobre a chacina do Benfica. O Povo, 10/3/2018. Disponível em https://www.opovo.com.br/noticias/ fortaleza/2018/03/o-que-se-sabe-ate-agora-sobre-a-chacina-do-benfica.html Acesso: 10 jun. 2018.

Crapanzano, Vincent (2003) Reflections on Hope as a Category of Social and Psychological Analysis. Cultural Anthropology v. 18, n. 1, p. 3-32.

DAS, V. (2007) Life and Words: Violence and the Descent into the Ordinary. Berkeley: University of California Press.

DERRIDA, J. (1979) Living On. In: Bloom, H. et al. Deconstruction and criticism. London \& New York: Continuum, 2004, pp.62-142.

FACINA, A. 2014. Sobreviver e sonhar: reflexões sobre cultura e "pacificação" no Complexo do Alemão. In: Fernandes, M.; Pedrinha, R. (Org.). Escritos Transdisciplinares de Criminologia, Direito e Processo Penal: bomenagem aos mestres Vera Malaguti e Nilo Batista. Rio de Janeiro: Revan, p. 39-47.

FELTRAN, G. (2012) Governo que produz crime, crime que produz governo: o dispositivo de gestão do homicídio em São Paulo (1992 - 2011). Revista Brasileira de Segurança Pública. v. 6, n. 2, pp. 232-255.

FÓRUM BRASILEIRO DE SEGURANÇA PÚBLICA. Anuário Brasileiro de Segurança Pública - 2017. São Paulo: Fórum Brasileiro de Segurança Pública, 2017.

GALDEANO, A. (2017) Voice and silence in the suburbs of São Paulo: State, community and the meanings of violence. In: Silva, D. (Org.) Language and Violence: Pragmatic Perspectives. Amsterdam \& New York: John Benjamins, pp. 57-78.

GRICE, H. P. (1989) Logic and Conversation. In Grice, H. P. Studies in the Way of Words. Cambridge, MA: Harvard University Press, pp. 3-143

LEAR, J. (2006) Radical Hope: Ethics in the Face of Cultural Devastation. Cambridge: Harvard University Press.

LEVI, P. (1988) É isto um bomem?. Rio de Janeiro: Rocco.

MACHADO DA SILVA, L. A. (1999) Criminalidade violenta: por uma nova perspectiva de análise. Revista de Sociologia e Política, n. 13, pp. 115-124. 
MAHMOOD, S. (2015) Religious Difference in a Secular Age: A Minority Report. New Jersey: Princeton University Press.

MAMDANI, M. (2014) When victims become killers: Colonialism, nativism, and the genocide in Rwanda. New Jersey: Princeton University Press.

MENEZES, P. (2015) Entre o "fogo cruzado" e o "campo minado": uma etnografia do processo de "pacificação" de favelas cariocas. Tese de doutorado, IESP, UERJ.

MESQUITA NETO, P. (2011) Ensaios sobre segurança cidadã. São Paulo: Quartier Latin.

MIYAZAKI, H. (2006) Economy of Dreams: Hope in Global Capitalism and its Critiques. Cultural Antbropology, v. 21, n. 2, p. 147-172.

MOITA LOPES, L.P. (2008) Uma Lingüística Aplicada Mestiça e Ideológica. In: Moita Lopes, L. P. (Org.). Por uma Lingüística Aplicada INdisciplinar. 2ed.São Paulo: Parábola Editorial, p. 13-44.

NANCY, J. The Ground of the Image. New York: Fordham University Press, 2005.

PAIVA, L. (2018) A miséria da segurança pública no estado do Ceará. Carta Capital, 30/1/2018. Disponível em http://justificando.cartacapital.com.br/2018/01/30/ miseria-da-seguranca-publica-no-estado-do-ceara/ Acesso: 10 jun. 2018

SCARRY, E. (1985) Body in Pain: e Making and Unmaking of the World. New York: Oxford University Press.

SILVA, D.; FACINA, A.; LOPES, A. (2015) Complex territories, complex circulations: The 'pacification' of the in Rio de Janeiro. Pragmatics and Society, v. 6, p. 175-196, 2015 .

SILVA, D. (2017) Investigating violence in language: An Introduction. In: Silva, D. (Org.) Violence and Language: Pragmatic Perspectives. Amsterdam \& Philadelphia: John Benjamins, p.1-29.

SILVERSTEIN, M. (1976) Shifters, linguistic categories, and cultural description. In: Basso, K.; SELBY, H. (Org.) Meaning in anthropology. Albuquerque: University of New Mexico Press, p.11-55.

TRIBUNA DO CEARÁ, 2018. Ato no Benfica. Disponível em https://web.facebook.com/ tribunadoceara/videos/1652340301526825/ Acesso: 10 Jun. 2018. 
VERAS, V. (2011). Verdade em tradução: um testemunho da dor das palavras. Trabalhos em Linguística Aplicada. v. 50, p. 459-478, 2011.

Recebido: 18/06/2018

Aceito: 10/07/2018 